\title{
A EDUCAÇÃO NA ÉPOCA DA CONECTIVIDADE EM REDE OU: QUE FIM LEVOU A AUTONOMIA?*
}

\author{
WolfGang LeO MAAR \\ Universidade Federal de São Carlos, São Carlos, São Paulo, Brasil
}

\begin{abstract}
Resumo: Neste texto, procura-se interpretar os rumos e as possibilidades da educação, conforme as tendências presentes sob as condições do que Manuel Castells denomina sociedade em rede. A análise se baseia em contribuições de Rousseau a Marx - sobretudo referentes à apreensão da autonomia e da sociedade - que conduziram à teoria crítica da sociedade, de Adorno e Marcuse. No capitalismo da sociedade em rede, houve uma transferência da prática das redes financeiras para as redes sociais, sem atentar à diferença entre o tempo das finanças e o tempo das vidas humanas. Em relação a esse quadro, procura-se apontar a atualidade da educação para a contradição e a resistência de Adorno, como processo educacional crítico, baseado na experiência da diferença e da contradição. Nela se contrapõem, de um lado, práticas combinadas com a educação existente na conexão em rede e sua participação virtual e, de outro, práticas alternativas em interações sociais objetivas e qualitativas.

Palavras-chave: Autonomia. Sociedade em rede. Participação. Theodor Adorno. Educação crítica.
\end{abstract}

Digo: o real não está nem na saída, nem na chegada; ele se dispõe pra gente é no meio da travessia. ${ }^{2}$ Aquela travessia durou só um instantezinho enorme. ${ }^{3}$

(Guimarães Rosa, Grande sertão: veredas)

O título deste trabalho é obviamente inspirado em um livro famoso de Walter Benjamin, A obra de arte na época de sua reprodutibilidade técnica. Para muito além do título, contudo, o texto procura se inspirar no prefácio "metodológico" da referida obra, em que o autor enfatiza que se encontra

\footnotetext{
* Artigo recebido em 18/8/2013 e aprovado em 12/10/2013.
} 
fora de seu propósito traçar um quadro do vigente, nem tampouco discorrer sobre uma eventual situação futura a se dispor como contraste ou aspiração. O que está em pauta é, antes, o foco nas tendências de desenvolvimento sob as condições atuais da produção capitalista (BENJAMIN, 2012, p. 11). Para adiantar a maneira de ver, presente neste esboço inicial de interpretação, ensaiado a seguir, cumpre acrescentar: produção compreendida seja nos termos da "produção na" sociedade vigente, seja nos termos da "produção da" própria configuração sócio-histórica, material e cultural dessa sociedade.

Além disso, mas não menos relevante, destaca-se a dialética da dinâmica tendencial apontada acima, que é tanto uma tendência à continuidade do existente mediante a anulação de eventuais forças contrárias, quanto uma tendência de transformação a partir do livre curso das contradições do vigente. Por certo, a continuidade reafirma o existente. Porém, ainda mesmo que ocorra uma prática transformadora, essa deverá se apoiar nas condições em vigor, desde que, é claro, sem reafirmá-las. Não há desafio maior - embora absolutamente necessário, como sustenta Herbert Marcuse em A ideologia da sociedade industrial - do que demonstrar a existência de tendências orientadas à emancipação no âmbito da dinâmica da sociedade estabelecida (MARCUSE, 1982, p. 233).

A apreensão das tendências de desenvolvimento da sociedade ocupa, de forma efetiva, um posto privilegiado, e sua compreensão tem uma história da qual urge se aproximar. Nesse sentido, as nossas considerações seguirão três passos:

1. apresentar elementos para pensar a educação no plano do desenvolvimento da sociedade burguesa moderna, em especial, no que se relaciona ao problema do nexo do desenvolvimento social com a ciência e a tecnologia;

2. traçar um quadro de algumas contribuições da teoria crítica, relevantes e decisivas ao tema em pauta, na época da sociedade de massa;

3. problematizar, com vista no anteriormente exposto, a questão da educação no campo contemporâneo da chamada "sociedade em rede", na era do capital financeiro e do "capitalismo informacional".

\section{EDUCAÇÃO E SOCIEDADE BURGUESA}

O pensamento de Jean-Jacques Rousseau parece especialmente indicado para iniciar a reflexão moderna acerca da nervura entre desenvolvimento social e desenvolvimento científico-tecnológico. Basta recorrer ao seu famoso e premiado ensaio que versa sobre as relações entre o aperfeiçoamento moral e o desenvolvimento das artes e técnicas. Não há exagero 
em afirmar que, se estivesse vivo, Jean-Jacques discorreria sobre as atuais tecnologias da informação.

Porém, o interessante é que a sua crítica à ausência de aperfeiçoamento moral é simultânea à inversão de orientação que ele propõe na dinâmica do contrato. A partir de Rousseau, o contrato, convertido em "contrato social", se estabelece no movimento orientado do povo ao soberano - "que povo e soberano fossem uma só pessoa" (ROUSSEAU, 1989, p. 29) - e não mais, como era usual, a partir do soberano. Esse é o cerne do Discurso sobre a origem e os fundamentos da desigualdade entre os homens. A questão da técnica se insere na questão social. Rousseau realiza um duplo movimento: não apenas toma como tema, de forma explícita, a questão da técnica; além disso, vincula a mesma ao plano social aprendido como gênese histórica. A concepção de uma "sociedade tecnológica", tal como sugere Marcuse, seria prenunciada, em certo sentido, nesse pensador. Trata-se de um homem a ser criado e uma "sociedade" a ser construída a partir da crítica à civilização, como alienação do estado natural. Construção, porém, com base em uma moralidade natural, a compaixão, pitié - "a piedade é um sentimento natural" (ROUSSEAU, 1989, p. 76).

A centralidade da questão social, expressa nessa inversão operada no contrato, será partilhada inteiramente por Kant que, entretanto, rejeita a existência de uma moralidade "natural". Para Kant, a moralidade seria também uma construção histórica dos homens; isso se depreende, de imediato, do famoso penúltimo parágrafo da Resposta à questão: o que é esclarecimento "Não vivemos numa época esclarecida, mas numa época em esclarecimento" (KANT, 1985, p. 112). Faltaria, além disso, muito para que os homens possam usar com autonomia seu entendimento, sem serem dirigidos por outros. Porém essa construção kantiana é estabelecida, ainda, em conformidade com "competências universais" dos homens, do gênero humano, como a liberdade. Essa "competência" estaria na universalidade da razão, em relação à qual a experiência é inapta e, por isso, exige o imperativo categórico formal.

No plano dessa edificação moral da sociedade, Kant apresenta a educação como dirigida não ao ser, à sociedade existente, mas ao dever-ser, a uma sociedade melhor, conforme consta de seus textos sobre pedagogia. ${ }^{4}$ Como destaca Marcuse, os termos do nexo entre educação e política parecem dispostos em um enquadramento que dificilmente poderia ser mais atual (MARCUSE, 1998, p. 172). Mas, em que pese essa atualidade, persiste, em Kant, uma perspectiva centrada em condições de uma possível realização, tomadas, de modo abstrato, no campo teórico. Seria um processo de exclusão da experiência, caracterizado pelos seus críticos como "formalismo da razão". 
Responsável por uma "moralização" abstrata da história, como assinala Nietzsche, ele propõe investigar, no lugar das condições de possibilidade abstratas, a "genealogia" da autonomia.

Mas, ainda entre seus contemporâneos, Kant enfrenta muitos críticos. Um dos mais notáveis, o poeta Schiller, afronta, sobretudo, esse divórcio entre os sentidos e a razão, ao propor, em suas Cartas para a educação estética do homem, uma educação dos sentidos: os homens devem aprender a desejar de maneira "elevada", racional - "desejar mais nobremente" (SCHILLER, 2011, p. 112). Não se trata de contrapor, de forma extrínseca, o mundo dos sentidos ao campo da razão; abre-se a perspectiva de pensar o "irracional", associado aos sentidos, no mesmo plano do "racional"; ou seja, ambos poderiam ser apreendidos como produção social dos homens em sua história. A realização da autonomia passa a ser um processo.

Hegel se apropriaria dessa nova maneira de situar o nexo entre universal e particular como processo educacional e formativo, presente em Schiller. Passa a pensar uma evolução humana em novos termos: conforme processos dinâmicos e não mais baseados em competências estáticas. $\mathrm{O}$ desenvolvimento se daria em instituições - tal qual o Estado e a família - como "formação" no âmbito das relações entre indivíduos e seus contextos sociais.

Essa é a grande inflexão realizada no pensamento hegeliano e que seria levada à frente, de maneira crítica, por Marx. Doravante o social precisaria ser apreendido na sua objetivação, como mediação e não mais como intersubjetividade de sujeitos dotados de competências estáticas. A sociedade não seria mais uma eventual construção a partir de homens autônomos. Ao contrário: seria apreendida como processo de formação, resultante da interação dialética entre os indivíduos e as objetivações institucionais de sua essência, a qual, assim, seria dotada de concretude real e histórica. É o que Hegel expressaria ao dizer que "o absoluto é sujeito"; o que tem em mente é o dever-ser, a autonomia, como sujeito, como processo em seu dinamismo.

Sociedade e indivíduo situam-se em nova aproximação "dialética" no plano dos nexos entre sujeito e objeto, em sua interdependência no campo de instituições. Hegel afirma que fortalecer o pensamento por si não basta, pois o pensamento autônomo não passa de ilusão, quando dissociado do conteúdo em que se abriga. Seria como uma viagem em que não se conhecem as cidades. Quando era diretor de ginásio, Hegel discorreu sobre o tema no Discurso de encerramento do ano letivo de 1809:

O progredir da cultura não pode ser visto como a tranquila continuação de uma cadeia em que os elementos seguintes se venham juntar aos anteriores [...]. Antes, pelo contrário, a cultura tem de ter uma matéria e um 
objeto anterior, sobre o qual trabalha, modificando-o e dando-lhe uma nova forma. É necessário que conquistemos o mundo da Antiguidade, tanto para o possuir, como ainda mais para ter algo que nós transformemos. Porém, para se tornar "objeto", a substância da natureza e do espírito tem que se ter posta defronte de nós, tem de ter recebido a forma de algo estranho. Infeliz aquele para quem o mundo imediato dos sentimentos se torna estranho [...]. - Para a alienação que é condição da formação teórica não se exige dor ética, nem o sofrimento do coração, mas, sim, a dor mais leve e o esforço da representação em se ocupar com o que não é imediato, com o que é estranho, com algo que pertence à recordação, à memória e ao pensamento. (HEGEL, 1994, p. 34)

Hegel expressa a experiência histórica de desenvolvimento do homem como o movimento de uma cultura - o "espírito" que não é espontâneo ou harmônico, mas perdição, esquecimento e reapropriação reflexiva. Através desse encontro com o outro, representado por perdição e esquecimento, chega-se a um momento de abertura para si mesmo. Esse processo é a formação cultural (Bildung); ele pressupõe que o espírito se aliene e que seu passado lhe pareça natureza exterior de que precisa se reapropriar. A totalidade desse processo, porém, só existe, especulativamente, no espelho do pensamento; apenas de modo ideal e não empírico, material.

Hegel apreende a autoprodução dos homens como processo de apropriação da essência humana, como objetivação objetivada que é alienada, como abstração no trajeto de formação do espírito. Em Kant, o indivíduo se subordina ao universal como ideia reguladora. Em Hegel, o universal adquire concretude no curso de um processo formativo-cultural. Na Fenomenologia do espírito, ele afirma que a educação já não é erguer-se do particular ao universal, como nos tempos antigos em que

o indivíduo se educava para a universalidade atuante em todos os aspectos do concreto; nos tempos modernos, ao contrário, o indivíduo encontra a forma abstrata pronta. [...] o trabalho, atualmente, não consiste tanto em purificar o indivíduo do modo sensível imediato e fazer dele substância pensada e pensante; consiste antes no oposto: [...] efetivar e espiritualizar o universal [...] ao tornar fluidos e dissolver os pensamentos fixos. (HEGEL, 1992, p. 39)

O universal da essência aparece no particular, porém não de forma imediata. Aparece apenas como mediação, na medida em que esse particular só adquire sentido na referência ao todo; esse, por sua vez, é uma construção especulativa do pensamento e, portanto, exige a participação do sujeito. É uma história que, ainda, não é história real, efetiva dos homens, como sujeitos pressupostos à sua história. É história enquanto ação geradora constituinte 
dos homens em uma objetividade pressuposta, estabelecida exteriormente a essa história. A objetivação da essência é uma objetividade pressuposta - o universal.

A história é como que "interior" ao universal. Mas o que importa é que essas são todas maneiras figuradas de expressar a inflexão operada pelo idealismo objetivo hegeliano: não é o dever-ser - a autonomia - que mobiliza, como em Kant; mas a contradição no plano do ser faculta a experiência da autonomia. Porém, Hegel é um idealista; o problema está em que ele pensa a mediação no plano do "espírito", cuja dinâmica é o desenvolvimento da razão no mundo. Os homens individuais precisam conhecer essa dinâmica do espírito - que se realiza em sua astúcia, por trás de suas costas - para se adequarem à mesma. Essa concepção de espírito é a "mãe", a matriz da apreensão moderna de ideologia.

A "razão" seria, então, plenamente histórica e realizada objetivamente. Isso pode ser acompanhado pela famosa equação hegeliana, presente no Prefácio da Filosofia do direito: "O racional é real e o real é racional" (HEGEL, s/d, p. 197). "O racional é real" lembra justamente a crítica a Kant e sua formalização; "o real é racional" indica a possibilidade de apreensão do real objetivo apenas como mediação, a partir do sujeito.

Com Hegel, o social deixaria de figurar no plano intersubjetivo para ser apreendido como objetivação, no plano do objeto. A racionalidade se realiza para além das participações individuais - por exemplo, no Estado - e cabe aos indivíduos compreender esse movimento da razão para poder ser um partícipe dessa dinâmica racional do mundo. O Estado existe como mediação na consciência individual, na qual é compreendido como sendo "afirmativo", valorizado para além das carências do plano do existente. Como apontará Marx, a formulação de Hegel é uma apresentação ideológica da sociedade burguesa objetivada no Estado, como um movimento de aproximação à autonomia - como autoprodução humana - apreendida como se fosse um ponto fixo, ideal, além da história.

Feuerbach e os chamados "hegelianos de esquerda" procurariam recuperar o materialismo - sensualista - no processo de autoprodução humana; contudo (e essa seria a principal crítica de Marx) ao preço de rifarem a mediação. Com acerto, Feuerbach faz a crítica da religião como pensamento de homens em sua existência material, no plano dos sentidos, projetado e objetivado exteriormente aos homens, como universal. Seria preciso criticar essa situação e trazer o universal divino à terra para possibilitar sua reapropriação humana. Assim o universal divino, objetivado fora dos homens, seria reconduzido para o seio dos mesmos. Contudo, a apreensão imediata 
do universal nesse objeto é ilusória, pois o objeto é uma objetivação. Pela sua dinâmica, o universal seria, de modo permanente, reconduzido no processo em que cumpre função de realização.

Para Feuerbach, haveria uma presença imediata do universal na realidade divina objetificada, como produto que poderia ser recuperado pelos homens para a realidade material. Mas, seguindo o procedimento de Feuerbach, a realidade material objetificada seria desprovida "de seu momento ativo", reflexivo, justamente aquele mobilizado pelo"idealismo" de Hegel. Esse momento ativo - a formação - seria a causa da objetivação que resulta no produto objetificado. Assim, nessa operação feuerbachiana não se explica a geração do objeto. Ou, como diria Marx, Feuerbach não explica por que os homens produzem a religião a que se subordinam. A alienação religiosa corresponde a uma alienação efetiva material, uma cisão insuperável no campo social e material, e não apenas a um produto alienado. Hegel, não obstante ser idealista, dá conta dessa objetivação, embora no plano do espírito, ideal.

Essa dupla frente de combate filosófico - com Hegel, em direção à matéria; e Feuerbach, em direção à atividade - constitui o cerne das famosas Teses sobre Feuerbach, de Karl Marx (1978). Elas são um ajuste simultâneo com o objeto como mediação idealista, e o objeto como imediato material.

Marx rejeita, como ineficiente, a apreensão imediata do universal - a conquista do Estado e da autonomia - conforme o materialismo sensualista de Feuerbach. A apreensão imediata obstrui a prática. É preciso tomar a objetividade como objetivação e, portanto, mediação para apreender a história da autoprodução humana. Marx insiste na mediação embora, ao contrário de Hegel, essa seja apreendida por ele como uma realização objetiva, ideológica, falsa na medida em que obstrui a apreensão do sujeito histórico efetivo, convertendo o mesmo em mero predicado. A alienação, também para Marx, não significa exteriorização, mas objetivação falsa da essência humana, coisificação dos homens, perda da sua atividade subjetiva em uma formação social reificada. O trabalho - que em Hegel é trabalho do espírito, formação como autoprodução humana -, a rigor, é trabalho alienado, autoprodução humana, pressuposta nos termos determinados da sociedade burguesa. Tal "trabalho do espírito", por sua vez, é gerado pelo verdadeiro processo de autoprodução humana: o trabalho material tal como exposto nos Manuscritos econômico-filosóficos (MARX, 1978).

Hegel apreende a autoalienação como exteriorização da essência, como objetivação, como efetivação. Em resumo, percebe - no interior da abstração - o trabalho como o ato autogerador do homem, o relacionar- 
se consigo mesmo como um ser estranho, e o manifestar-se como um ser estranho, como consciência genérica e vida genérica.

Entretanto, esse ato aparece, em primeiro lugar, como ato apenas formal, porque abstrato, porque o próprio ser humano só tem valor como ser abstrato pensante, como consciência-de-si. Em segundo lugar, como a concepção é formal, abstrata, a superação da alienação converte-se em uma confirmação da alienação. [...] em sua forma abstrata, como dialética, esse movimento é tomado assim pela vida verdadeiramente humana, mas, como essa é uma abstração, uma alienação da vida humana, essa vida é considerada um processo divino, um processo que perfaz a própria essência do homem, distinta dele, abstrata, pura, absoluta. Em terceiro lugar, esse processo deve ter um portador, um sujeito; mas o sujeito só aparece enquanto resultado; e esse resultado, o sujeito que se conhece como consciência-de-si absoluta é, portanto, o espírito absoluto, a ideia que se conhece e atua. O homem efetivo e a natureza efetiva convertem-se simplesmente em predicados, em símbolos desse homem não efetivo, escondido e dessa natureza não efetiva. Sujeito e predicado têm, assim, um com o outro, relação de uma inversão absoluta: sujeitoobjeto místico ou subjetividade que transcende o objeto; o sujeito absoluto como um processo, como sujeito que se aliena e volta para si na alienação, mas que, ao mesmo tempo, a retoma em si; e o sujeito como processo, o puro, incessante girar dentro de si. [...] A atividade plena de conteúdo, viva, sensível e concreta da auto-objetivação converte-se em sua pura abstração [...], pensada como tal e convertida em atividade autônoma (destaques - WLM) (MARX, 1978, p. 45-46).

Nesse trecho exemplar da crítica de Marx a Hegel, aparece, com toda clareza - como enfatizado especialmente nos trechos destacados -, porque Hegel é o ideólogo da sociedade burguesa. Explicita o papel da dialética da objetivação como construção ideológica e sua prática - com sua aparência autônoma, embora seja formal e abstrata - que se sobrepõe à objetividade material, viva, na qual ocorre o processo efetivo de autogeração humana dos homens em interação entre si e com a natureza.

Em face de tudo isso, adquire relevância decisiva a oitava das Teses sobre Feuerbach:

Toda vida social é essencialmente prática. Todos os mistérios, que induzem às doutrinas do misticismo, encontram sua solução racional na práxis humana e no compreender dessa práxis. (MARX, 1978, p. 52)

Marx considera insuficiente apenas uma crítica ao Estado, em que a práxis que esse significa na formação social é intocada. A crítica só se 
torna efetiva quando igualmente se dirige à "compreensão dessa práxis" do Estado. Na "compreensão" hegeliana da práxis se situa a imposição do Estado vigente sobre a própria prática, como imposição objetiva; a prática, nesse caso, se resume ao âmbito do existente, e não incide na própria produção histórica deste último. A autonomia e sua experiência estariam, assim, comprometidas em uma realidade objetiva que se impõe como formação ideológica conservadora. Por isso, a crítica política deve ser acompanhada de uma crítica da "consciência", isso é da cultura e da ideologia que se sobrepõem como objetivações ideológicas ao processo social efetivo.

\section{EDUCAÇÃO E SOCIEDADE DE MASSA}

A Teoria crítica da sociedade, posteriormente conhecida como Escola de Frankfurt, tem em vista, desde o início, criticar e superar o que foi antes destacado como uma "compreensão idealista da práxis".

Horkheimer e Adorno retornam à questão logo no Prefácio à Dialética do esclarecimento, ao sublinharem sua preocupação com o que denominam "a consciência vigente" (HORKHEIMER; ADORNO, 1986, p. 11). Vale dizer a "compreensão existente da práxis"; por um lado, "a disposição enigmática das massas educadas tecnologicamente a deixar dominar-se" (p. 13); por outro, "a difusão hipócrita do espírito. Sua verdadeira aspiração é a negação da reificação. Mas ele necessariamente se esvai quando se vê concretizado em um bem cultural e distribuído para fins de consumo" (p. 14). Não que antes houvesse uma adesão estrita à compreensão idealista da práxis.

No primeiro quadrante do século XX, a obra de Georg Lukács, em especial a partir de História e consciência de classe, se debruça sobre a herança a-crítica do idealismo sobrevivente na concepção materialista-histórica. Mediante sua categoria de "reificação" - ou coisificação, em uma versão literal de Verdinglichung -, Lukács conduz ao âmbito "subjetivo" a análise do fenômeno da inversão objetiva - apreendido, no plano da reprodução do modo de produção capitalista, como"novo objeto", centralizador e catalisador do capitalismo pela definitiva contribuição de Karl Marx. Ao propor uma apreensão da sociedade, ela própria como "mediação reificada”, Lukács nela inclui as formações reificadas da teoria que deveria dar conta da configuração social. ${ }^{5}$ Assim, conduz à necessidade de um prisma da "totalidade", em substituição à perspectiva anterior centrada na economia, para focalizar as tendências de desenvolvimento da sociedade; o processo de alienação também diz respeito ao plano da teoria e do "espírito" em geral.

Nesse prisma da totalidade, uma vez que a própria cultura como âmbito da "consciência" participa do processo de reprodução falseadora 
da produção capitalista, também haveria a necessidade de apresentar uma prática emancipadora no campo cultural. Lukács proporia uma ação cultural revolucionária - pela qual se pudesse garantir aos trabalhadores acesso ao que seria uma cultura não reificada: a cultura clássica e dos primórdios da "modernização" capitalista - como modo de impulsionar uma conscientização de mobilização contra a dominação promovida na sociedade capitalista contemporânea de sua época, não só no plano econômico, mas inclusive no campo da reificação cultural.

Essa seria a inspiração que forma o germe da teoria crítica, conforme sua apresentação resumida no programa exposto em Teoria crítica e teoria, redigido por Max Horkheimer em 1937. Já a Dialética do esclarecimento, à sua maneira, apontou a dimensão mais propriamente social na iniciativa, em sua origem, "crítica teórica". Nesse sentido, enfatiza o processo de reificação no plano da própria formação da subjetividade, pela dominação em sua mediação subjetiva, tanto na "indústria cultural", quanto no processo de semiformação ou semicultura (Halbbildung), que são inovações conceituais, ambas presentes na citada obra. ${ }^{6}$ Será TheodorW. Adorno quem conduz esse nexo entre esfera cultural e esfera social ao novo patamar exigido na nova tendência do desenvolvimento da produção capitalista, que é a sociedade de massa, principal característica social do século XX.

Em Minima moralia, em especial no parágrafo "Novissimum Organum", Adorno (2008, p. 226) atentara - para a questão da construção reificada da subjetividade e, portanto, da "consciência" - que essa não seria atinada devidamente, nos termos propostos por Lukács, na sociedade capitalista de então. Assim finaliza o livro com a indicação da insuficiência de práticas "conscientizadoras", pleiteando, em seu lugar, por uma práxis de "redenção" (Erlösung = salvação). Essa indica a necessidade de superação de uma situação social complexa de dominação, para"construir perspectivas em que o mundo se ponha alheado, com suas fendas e fissuras à mostra"; uma perspectiva em um lugar "afastado da existência" e que precisa "primeiro ser arrancado daquilo que existe" (ADORNO, 2008, p. 245). A recusa da crítica cultural ideológica apontada acima se coloca com toda sua clareza no ensaio Crítica cultural e sociedade (1986), em que Adorno explicita a reconceituação necessária no plano da apreensão da ideologia. A crítica ideológica doravante seria inofensiva diante de uma ideologia que, como

aparência socialmente necessária, é hoje a própria sociedade real, na medida que o seu poderio integral e o seu caráter inelutável, a sua existência em si preponderante, substitui o sentido por ela própria arrasado. (ADORNO, 1986, p. 88) 
Assim, não é a"ideologia em si que seria falsa, mas a sua pretensão de coincidir com a realidade" (p. 89). A novidade dessa apreensão da ideologia como "cópia falsa do mundo", como mundo gerado nos termos do modo de produção capitalista e que se impõe como única referência - constitui uma chave fundamental para a apreensão da educação, conforme Adorno. Como visto antes, Marx já apreendera a ideologia nesses termos e havia adiantado a necessidade de estender a crítica a esses parâmetros. Assim se expressa na terceira das Teses sobre Feuerbach, referência básica nas análises da educação: a doutrina materialista sobre a mudança de contingências e da educação se esquece de que tais contingências são mudadas pelos homens e de que o próprio educador deve ser educado. Deve, por isso, separar a sociedade em duas partes - uma das quais é colocada acima da outra. A coincidência da alteração das contingências com a atividade humana e a mudança de si próprio só pode ser captada e entendida racionalmente como práxis revolucionária (MARX, 1978, p. 51).

Na tentativa de atualizar sua leitura de Marx, o frankfurtiano insiste, contudo, no que podemos chamar de objetivação social dessa "práxis revolucionária". Vale dizer: enfatiza a ten dência à "ideologização capitalista" (ou reificação) da própria práxis, doravante a serviço da reprodução do vigente, na era do que seria o capitalismo avançado dos tempos de Adorno. Em outras palavras: o capitalismo se apropria da crítica e a reconstrói à sua maneira ideológica. O predomínio do ser sobre a consciência tem sido utilizado, sobretudo, como reafirmação da sociedade vigente, destacaria Adorno no mesmo texto em que insiste na nova apreensão de ideologia. Em suma: assim como a apropriação das condições vigentes não pode ser "imediata", também a "práxis revolucionária" exige a apreensão das mediações sociais em cujo campo se situa; por essas mediações realiza-se a inversão ideológica e, nelas, ela poderia ser superada.

No ensaio Educação após Auschwitz (1995), Adorno insiste: o imperativo de que Auschwitz não se repita é primordial à educação, implica influir nas condições dessa repetição, nas condições de sua produção. $O$ diálogo implícito no texto de Adorno com a famosa expressão de Marx contida no 18 Brumário de Louis Bonaparte (MARX, 1978, p. 329), segundo a qual os homens fazem sua história mas não conforme condições de sua livre escolha - versa justamente sobre as imposições da sociedade que implicam a anulação da autonomia. A questão posta diz respeito às condições sociais que implicam a repetição de Auschwitz: enquadramento em um coletivo, frieza, individualização sem individuação, educação agonística regida só pela competição. 
Em um debate publicado sob o título Educação contra a barbárie (1995), Adorno avança ainda mais: as condições de repetição de Auschwitz são as da perpetuação socialmente impositiva da barbárie. A imposição da organização social se explicita como falência da cultura, enquanto essa é um modo de lidar com a alienação. Em vez de cumprir a promessa de prover os homens com racionalidade para se contrapor à realização de fins que os subjugam, recompondo a harmonia de suas relações, a cultura proporciona a divisão dos homens e reafirma o existente. $O$ que seria, antes, um processo emancipador de formação, apto a facultar uma autonomia em relação às imposições sociais, agora, seria uma formação pervertida, geradora de barbárie, reprodução da sociedade heterônoma, na qual os homens fazem a si mesmos, coletivamente, o que a imposição social Ihes impõe como jugo da sociedade organizada.

O problema é que a realidade social apreendida pelos homens como mediação objetiva reificada - ou seja, como sociedade organizada que se impõe e sobrepõe ideologicamente ao social - influi sobre os indivíduos. Essa influência afeta a sua aptidão à experiência, obstruindo a mesma em sua capacidade de contrapor e experimentar, de modo transparente, a diferença entre os objetivos socialmente impostos e aqueles que corresponderiam a fins racionais da sociedade.

No debate intitulado Educação - para quê? Adorno afirma:

Penso, sobretudo, em dois problemas difíceis, que é preciso levar em conta quando se trata de emancipação:

Em primeiro lugar, a própria organização do mundo em que vivemos é a ideologia dominante - hoje muito pouco parecida com uma determinada visão de mundo ou teoria -, ou seja, a organização do mundo converteu-se a si mesma, imediatamente, em sua própria ideologia. Ela exerce uma pressão tão imensa sobre as pessoas que supera toda educação. [...] No referente ao segundo problema [...] emancipação significa o mesmo que conscientização, racionalidade. Mas a realidade sempre é simultaneamente uma comprovação da realidade (uma maneira de pôr a realidade à prova - WLM), e essa envolve continuamente um movimento de adaptação.

A educação seria impotente e ideológica, se ignorasse o objetivo de adaptação e não preparasse os homens para se orientarem no mundo. Porém ela seria igualmente questionável se ficasse nisso, produzindo nada além de pessoas bem ajustadas, em consequência do que a situação existente se impõe precisamente no que tem de pior.

Nesses termos, existe no conceito de educação [...] uma ambiguidade. Talvez não seja possível superá-la no existente, mas não podemos nos desviar dela. (ADORNO, 1995, p. 143) 
Logo em seguida acrescentaria:

Aquilo que caracterizaria propriamente a consciência é o pensar em relação à realidade, ao conteúdo - a relação entre as formas e estruturas de pensamento e aquilo que esse não é. Esse é o sentido mais profundo de consciência [...] não é apenas o desenvolvimento lógico-formal, mas ele corresponde literalmente à capacidade de fazer experiências. Eu diria que pensar é o mesmo que fazer experiências intelectuais. (ADORNO, 1995, p. 150)

Adorno propõe a aptidão à experiência como objetivo principal para a educação. A educação tem o momento da adequação, sem o qual seria impossível; mas tem também o momento da contradição, da resistência, da diversidade e da variação. A "experiência do não eu no outro" (ADORNO, 1995, p. 154). Entretanto a adaptação necessária não pode ser reafirmação de conformidade, ou seja: conformismo. Antes, seria preciso "colocar no lugar da adaptação uma concessão transparente a si mesma onde isso é inevitável, e em qualquer caso confrontar a consciência desleixada" (p. 154). É preciso se opor à possibilidade de uma harmonia entre o que funciona em sociedade e o homem em sua formação autônoma. A educação teria mesmo que"trabalhar em direção dessa ruptura, procurando torná-la consciente em vez de dissimulá-la" (p. 154).

Desse modo, seria viável uma outra objetivação ou mediação social, objetivando adquirir a função de "sociedade", libertando-nos do "sempre igual" - a "compreensão da práxis" como sendo a da práxis que se impõe socialmente. Transitaríamos, assim, da conscientização à redenção. Essa seria a leitura de Adorno da $11^{\text {a }}$ Tese sobre Feuerbach, em que Marx insiste na necessidade de superar a apreensão do mundo, baseada na interpretação do mesmo; adaptação essa quando o importante é sua apreensão no campo da transformação, pela experiência da contradição e diversidade.

A dimensão subjetiva implícita nessa mediação social alternativa é justamente uma reconstrução da autonomia em tempos de totalização da imposição social, tal como explicitado pelo recurso exemplar a Auschwitz. No debate Educação e emancipação, Adorno explica que

no referente à pergunta "Vivemos em uma época esclarecida?" Kant respondeu: "Não, mas certamente em uma época de esclarecimento". Nesses termos, ele determinou a emancipação de uma maneira inteiramente consequente, não como uma categoria estática, mas como uma categoria dinâmica, como um vir-a-ser e não um ser. Se atualmente ainda podemos afirmar que vivemos em uma época de esclarecimento, isso tornou-se altamente questionável em face da pressão inimaginável exercida sobre as pessoas, seja simplesmente pela própria organização do mundo, seja num sentido 
mais amplo, pelo controle planificado até mesmo de toda realidade interior pela indústria cultural. [...] é preciso começar a ver efetivamente as enormes dificuldades que se opõem à emancipação nessa organização do mundo. (ADORNO, 1995, p. 181)

O motivo, por certo, é a contradição social; a organização social em que vivemos continua sendo heterônoma, isso é, nenhuma pessoa pode, de fato, existir na sociedade atual conforme suas próprias determinações; enquanto isso ocorre, a sociedade forma as pessoas mediante inúmeros canais e instâncias mediadoras, de modo tal que tudo absorvem e aceitam nos termos dessa configuração heterônoma que se desviou de si mesma em sua [das pessoas] consciência (p. 181).

A educação meramente escolar - nas instituições existentes não forma, diria Adorno; porque há uma alteração na "consciência" - na "compreensão da práxis" antes referida por Marx - pela qual as próprias pessoas agem para que a sociedade se imponha, e não elas mesmas. No sentido de modificar essa situação - a reificação operada em última análise nos termos do fetichismo da mercadoria -, cabe à educação um importante papel: recuperar a experiência da contradição social, agora uma experiência autônoma, pois contrária à experiência da consciência vigente em sua inversão.

Adorno insiste na meta de educar para a experiência autônoma, reprimida na sociedade heterônoma. Experiência autônoma significa ter como alvo uma crítica às mediações que obstruem a emancipação, na medida em que excluem o diverso que contraria. Por isso trata-se de uma "educação para a contradição e a resistência" (p. 183) em relação à organização social vigorante; tanto pela organização do pensamento - mediante um pensamento negativo, contestador, como queria Adorno - quanto pela organização da experiência sensível - por meio de uma "nova sensibilidade", como queria Marcuse. Por essa experiência autônoma, pode-se adquirir realidade efetiva, uma objetivação social como nova mediação.

\section{EDUCAÇÃO E SOCIEDADE EM REDE}

Em obra central sobre o capitalismo avançado ou tardio, A ideologia da sociedade industrial, Marcuse (1982) apresenta uma sociedade "sem oposição", isso é, uma formação social que controla e torna inofensivas ações de contraposição ao existente a partir de sua própria organização tecnológica. O pressuposto que sustenta tal concepção estaria em uma mudança na apreensão da tecnologia e da ciência, que deixariam de pertencer à dinâmica 
de geração da formação social, ao revolucioná-la de modo a gerar forças contraditórias às relações sociais conservadoras.

No novo quadro do capitalismo visado por Marcuse, a tecnologia torna-se força produtiva e restringe, portanto, sua atuação frente à própria sociedade existente, a que o autor, inclusive, denomina "sociedade tecnológica" (MARCUSE, 1998, p. 164). A ciência convertida em tecnociência já não estaria no campo-fim da produção de conhecimento e de seu conteúdo de fato, mas no plano da organização social tecnológica, em total vinculação ao processo capitalista, no qual se torna apenas meio de acumulação de capital. Sem dúvida, um dos resultados mais notáveis dessa metamorfose é o questionamento do progresso tecnológico, que agora seria conduzido estritamente como crescimento econômico. Como base desse questionamento, há uma concepção de tempo compreendido, de forma precisa, no plano do processo de valoração capitalista.

Na Fundamentação da metafísica dos costumes, Kant afirma que "tudo tem ou um preço ou uma dignidade [...] A moralidade e a humanidade, enquanto capaz de moralidade, são as únicas coisas que têm dignidade" (KANT, 1974, p. 234). Desse modo, ele procura explicitar uma tensão existente entre o"tempo do homem" (com a dignidade, fundamento da sua autonomia, como fim em si mesmo) e o "tempo da mercadoria" (com o preço pelo qual qualquer coisa pode ser posta como equivalente em seu lugar). No tempo humano, o indivíduo, com sua subjetividade, tem a possibilidade de apresentar uma verdade como potencial das condições da realidade; essa é a sua autonomia de propor leis para seu próprio vir-a-ser. No tempo mercantil, existe apenas o momento de representação de uma verdade na objetividade existente da troca por um equivalente no mercado. É, pois, na arte que se unem esses dois momentos, de apresentação e de representação. O processo de formação tem justamente a função de cultivar nos homens a adequação do momento de representação e a crítica do momento de apresentação. Na situação de barbárie, como Auschwitz, o processo formativo é mutilado em sua subjetividade - a chamada "fraqueza do eu"; em seu lugar ocorre a semiformação, pela qual os homens só fazem a si mesmos o que a sociedade Ihes impõe, só representam o vigente, sem poder apresentar qualquer tentativa de ir além. Por isso Adorno afirma que, após Auschwitz, escrever poesia é barbárie.

Junto com a tendência à exclusividade do tempo do preço e da mercadoria, ocorre uma progressiva tendência à integração de todos os valores culturais nos moldes existentes, com a exclusão das experiências de contradição. Pela obstrução das contradições, essa tendência conduz a uma 
ruptura com a situação de tensão em que ser e dever-ser se contrapõem. Assim, os conteúdos culturais bem como a tecnologia se tornam meros veículos de adaptação. Seria esse o plano de uma falência da cultura e da formação, tal como apresentadas antes; seria o plano de um esclarecimento - com os dois momentos assinalados - que se reverte em barbárie.

O quadro explicitado, tanto por Marcuse quanto por Adorno e outros, constitui um "novo espírito do capitalismo" na era da economia monopolista, em comparação com o período da chamada economia liberal de mercado anterior e seu próprio "espírito". Esse "novo espírito" se manifesta, sobretudo, no campo do desenvolvimento da sociedade de massa, com a construção da chamada sociedade do bem-estar, e do consumo de massa, característico do período dos trinta "anos de ouro" da sociedade capitalista do pós-guerra. $\mathrm{O}$ consumo, atrelado aos avanços técnicos, de modo funcional, estaria vinculado à luta de classes como obstrução dos vetores de oposição.

Essa noção de "espírito do capitalismo" visa expor os nexos objetivos e subjetivos em que se apresentam as condições de efetivação do modo de produção capitalista. Deriva da concepção do espírito hegeliano e seria remodelada conforme a apresentação das possibilidades e dos limites da acumulação capitalista em A ética protestante e o espírito do capitalismo, de Max Weber (2004). Essencial é tentar acompanhar a tendência dinâmica da acumulação no âmbito do jogo de forças, como reação, adequação e redimensionamento do processo capitalista no campo histórico sociopolítico da luta de classes. Vencida a era inaugural da expansão da sociedade do consumo de massa e da captura tecnológica de ciência e cultura, estaríamos, agora, frente a novos desafios para o processo de acumulação do modo de produção capitalista. Isso resultaria em uma terceira versão do "espírito do capitalismo", exposta agora em O novo espírito do capitalismo, de Boltanski e Chiapello (2009).

Hoje estaríamos em uma nova época, a "era da informação", a que corresponde uma "sociedade em rede", conforme o que Manuel Castells batizou como um "capitalismo informacional". A nova era constitui um aprofundamento da situação tecnológica anterior, mas com um agravante na tendência à ideologização totalizante; a crítica se torna ainda mais difícil em face da abrangência das relações de equivalência no campo virtual.

Nesse agravante, a própria práxis, enquanto tal, seria reificada, submetida a um processo de objetivação. Nele, a prática aparentemente autônoma - exemplificada como prática participativa na própria organização empresarial vigente - se converte em "participação" que seria universalizável no plano virtual. Marcuse ainda previa a possibilidade de retirar o plano da práxis da 
imposição do domínio tecnológico-social, mediante o que propunha ser uma "grande recusa" (MARCUSE, 1982, p. 235). Entretanto, a reflexão de Marcuse ocorre em uma dimensão dupla: a dimensão da sociedade instalada e a dimensão da construção social, histórica e material dessa sociedade instalada; elas fazem o papel antes contemplado pela dimensão da representação e da apresentação. A "grande recusa" refere-se, em última análise e de forma específica, à recusa da dimensão da sociedade vigente, com a procura de alguma alternativa potencial, mediante uma reinserção no plano em que ocorre a produção do vigente.

Essa maneira de apreensão do social diferencia a perspectiva de Marcuse e Adorno das abordagens de Castells, Boltanski e Chiapello. Para os últimos, o capitalismo se renova a partir da sua crítica mediante novas formas de controle e de cooptação da força de trabalho, removendo obstáculos, mas sem questionar a essência da estrutura capitalista de dominação existente no tempo mercantil. Há uma aproximação afirmativa da reço comercial sociedade vigente. As críticas - em grande parte voltadas à intensidade da presença da sociedade de consumo de massa - resultariam em reivindicações de diferenciação e desmassificação no final do período de expansão capitalista, no entender de Adorno e Marcuse. A resposta do capitalismo seria uma "mercantilização da diferença"; essa mercantilização converte "bens e práticas - que, em outra situação, ficaram fora do mercado" - em produto dotado de p (BOLTANSKI; CHIAPELLO, 2009, p. 444). Contudo, por essa via, o pressuposto dos autores é a existência de uma base comum, praticamente natural e indiscutível, assentada na universalidade da quantificação que acompanha o processo de valoração.

Ora, essa pretensa universalidade não pode ser aprendida como disponibilidade imediata. Ao contrário, (como vimos anteriormente) constitui uma objetivação, uma mediação socialmente construída e que se converteu em ideologia como expressão do modo de produção capitalista. Ela implica perda da aptidão à experiência daquilo que não se encontra, por completo, desvirtuado pelo processo de acumulação; esse, uma vez em vigor, impõe padrões de uniformização que deslocam a experiência da diversidade e da contradição. Assim, não ocorre a imposição de padrões de troca ao âmbito de diferenças em relação a um plano que (embora ainda não o seja de forma plena) já é, em essência, potencialmente mercantil. O que se enseja é impor ao que está fora - de modo essencial e não acidental - do campo mercantil os termos de uma experiência obstruída na esfera das metamorfoses desse plano de mercado. Essa obstrução impede a experiência da realidade social não mercantilizada, reforçando sua aparência irreal, ilusória e fantasiosa 
para os partícipes concretos do processo produtivo. A experiência se limita à "participação ou não participação" nos procedimentos interativos, comunicativos e informativos da sociedade vigente.

A "mercantilização da diferença", como é denominada, a rigor, constitui uma anulação da diferença resultante da sua conversão em mero diferencial quantitativo, indiferente a quaisquer diferenciações qualitativas. Anula-se, assim, frente à ausência de um outro, a possibilidade da formação da autonomia.

O que, de imediato, parece processo de imposição mercantil é essencialmente mediação. Ou seja: a imposição também acontece como uma "educação"; não é uma tendência espontânea ou natural. Falar de autonomia implica saber quem é o sujeito dessa mediação. É uma objetivação reificada que inverte o nexo sujeito-objeto, obstrui a experiência e constitui imposição da forma hegemônica da acumulação no atual desenvolvimento do modo de produção capitalista. Está em pauta, então, a imposição progressiva do processo de acumulação financeira, pela qual, de modo aparente, gera-se riqueza sem recorrer à produção. Concentra-se, portanto, na imposição de padrões de uniformização nos termos do valor, que atuam à distância e boicotam a formação da experiência; essa seria fundamental para a apreensão da diversidade e da contradição por parte dos sujeitos efetivos da produção, os trabalhadores.

Castells chega à denominação "capitalismo informacional"justamente pela ênfase na prática das redes financeiras no atual processo de acumulação do capital, como revela em sua obra (CASTELLS, 2010a, p. XXVI). No entanto, falha em reinserir a acumulação financeira no processo de valoração do capital e (como no caso de $O$ novo espírito do capitalismo) logo procura derivar da mediação - a "rede" - as novas formas de dominação. Então, essa seria -em substituição à autoridade, seja patriarcal tradicional, seja dos meios de comunicação de massa vigentes - a "centralidade imaterial" dos "códigos culturais, mediante os quais as pessoas e as instituições representam a vida e tomam decisões". Leia-se: o poder da capacidade de multiplicação de informações em rede. Nela, como se sabe, cada vez que alguém interage com um conteúdo no Facebook, por exemplo, esse aparece em sua time-line e acaba percebido pelos seus contatos, acumulando exponencialmente o número de pessoas impactadas. Ou seja:"o poder reside nas redes de troca de informação e manipulação de símbolos que estabelecem relações entre atores sociais, instituições e movimentos culturais por intermédio de ícones, porta-vozes e amplificadores intelectuais" (CASTELLS, 2012, p. 425). Mas Castells não fala das características dessas "relações" assim estabelecidas; nelas o avanço na 
quantidade de informações corresponde a um recuo da qualidade da prática. Como seu tempo é o tempo do preço e da quantidade, não há trajeto no plano de diferenças qualitativas. A prática de quem é "educado" nos termos da rede é imediata, instantânea e se esgota no mesmo plano de que resulta: um campo de troca virtual em que não ocorre uma interação entre sujeitos "vivos e concretos", para parafrasear Marx, nos Manuscritos, como já visto. Não existem as condições para o potencial formativo. Os protestos, os conflitos, as mobilizações convocadas nas redes sociais seriam, por essa via, desviados de sua função de crítica às imposições sociais objetivas vigentes, para se tornarem formas de participação na formação social que existe. Isso ocorre porque o vigente é apreendido de modo abstrato, como campo virtual, e não como objeto que mantém uma relação de diversidade com o plano objetivo do sujeito; sujeito que também é mero partícipe de uma mobilização, sem participação objetiva, mas apenas virtual.

A forma tecnológica da "sociedade em rede" - da "sociedade tecnológica", como diria Marcuse - se sobrepõe à sociedade como sua "forma ideológica". A pergunta que importa é: Qual a forma social dessa esfera pública, imposta como "capitalismo informacional", na fase financeira do modo de produção e acumulação do capital? Cabe, sobretudo, apreender a mesma como mediação, isso é, como "metamorfose do capitalismo" em que se mantém a dominação exercida sobre a força de trabalho pelo capital, mas dominação que é produzida historicamente pelos próprios homens. Com certeza, derivam, daí, mudanças de posição econômica - substituição de serviços por processos informatizados -, mas também o que talvez seja mais decisivo: mudanças que implicam "deteriorações sociais da dominação do capital" (BRUNHOFF, 2010, p. 93).

Nesse sentido, retomamos agora o tema central da educação na era da sociedade tecnológico-informacional.

O risco não está apenas na perda do controle, na alienação da centralidade da multiplicação das informações em rede; essa centralidade da multiplicação em rede já é um risco em si, uma alienação. Mas uma alienação decorrente, de modo fundamental, do avanço da acumulação financeira do capital no modo de produção capitalista vigente; uma tendência à abstração progressiva da produção de valor em relação à produção efetiva no plano do trabalho, como transformação material que visa à geração de valores de uso. Por seu intermédio, instala-se uma nova forma de "inserção social" - que é ideológica - a qual, ao promover uma inversão na relação sujeito-objeto, a rigor, sustenta uma exclusão real da práxis efetiva sob a forma de uma aparente participação. 
A questão posta pela "sociedade em rede", em certo sentido, lembra a questão da televisão. A televisão, como bem destacou Adorno, não deve ser tomada de forma isolada, mas no plano de uma cultura de massa que se impõe permanentemente aos indivíduos na sociedade contemporânea. A televisão também "educa": essa é a questão. No entanto, pela fartura de sua oferta - e nisso se identifica às redes sociais contemporâneas -, ao se aproximar das condições sociais vigentes, obstrui nelas qualquer experiência de diversidade e contradição, mediante rearranjos e mudanças de acento; ou seja, por meio da organização que impõe. Nesse sentido, a sociedade reconstruída pela televisão é uma objetivação ideológica da coletividade, em cujo lugar se apresenta. Ela ocupa o âmbito de uma esfera pública que muda de função crítica para função de legitimação - como analisado no livro de Habermas, Mudança estrutural da esfera pública. ${ }^{7}$ Algo análogo ocorre com a "sociedade em rede que

incute nas pessoas uma falsa consciência e um ocultamento da realidade [...] além de procurar impor às pessoas um conjunto de valores [...] enquanto a formação consistiria justamente em pensar problematicamente conceitos que são assumidos apenas em sua positividade, possibilitando adquirir um juízo independente e autônomo a seu respeito. (ADORNO, 1995, p. 80)

No caso das redes sociais há uma tendência à integração dos valores no espaço virtual, em decorrência da própria distância entre as práticas virtuais e o plano da produção da experiência social material. Disso resulta um divórcio entre tempo da rede e tempo da experiência.

Para exemplificar, basta indicar como nas redes sociais se gera um novo uso da palavra "amigo", como lembra Michel Serres em Polegarzinha (SERRES, 2013, p. 71); ou como nelas se transformam as próprias "relações de experiência" na explicação de Manuel Castells (CASTELLS, 2012, p. 425). No capitalismo informacional, houve uma transferência da prática das redes financeiras para as redes sociais, desprovida de atenção à diferença entre o tempo das finanças e o tempo das vidas humanas.

Há uma mimetização das imposições sociais no comportamento dos indivíduos; esses, como antes exposto na referência a Adorno, fazem em relação a si mesmos o que a sociedade lhes impõe. O problema, como Castells inclusive reconhece, reside em que, tanto em relação aos "amigos" quanto no caso das "relações de experiência", há uma estruturação nos termos de uma concepção de tempo - "glacial e atemporal" - imposta pelo próprio veículo tecnológico (CASTELLS, 2010a, p. XXVIII). Tempo construído como uma nova sequência que isola, abstrai e se impõe à totalidade das práticas sociais, sepultando, de vez, a experiência do tempo essencial ao processo 
formativo. Da fraqueza para o tempo, característica da semiformação, transitamos à rendição ao instante, à imediatez da participação em rede. Já não haveria, apenas, um controle sobre a "oposição", como denuncia Marcuse, mas um controle sobre a própria "participação", agora, uma prática apenas aparentemente autônoma na rede.

Como em O novo espírito do capitalismo, Castells não compreende essa nova "consciência" no âmbito de uma disputa dinâmica de forças, inclusive, no campo da geração da sociedade; ele se restringe ao plano social estabelecido. Nesses termos, embora mencione a necessidade de"sobreviver ao capitalismo" (CASTELLS, 2010b, p. 426) e um plano da política para além das redes, não confere ao mesmo qualquer poder de determinação (p. 372). Não existe a possibilidade de uma contraposição entre os dois campos. Assim, Castells autolimita suas possibilidades, já que não há uma crítica imanente possível, quer da televisão, quer das redes sociais. Nelas, a percepção e a participação são organizadas de modo a impossibilitar a experiência para quem se move, de modo exclusivo, no plano da objetivação ideológica da sociedade, tal como a rede social, por exemplo. Sua organização precisa recuperar os vínculos existentes com a esfera produtiva, com a produção, para que a "compreensão da práxis" possa abandonar o âmbito de relações meramente entre os produtos.

É preciso "levar a sério a nova forma do capitalismo mundializado" como, de maneira apropriada, pede Leda Paulani (OLIVEIRA, 2007, p. 45). Porém, o problema já não reside, como ela parece sugerir, na crítica à política reduzida, à forma de "espetáculo cultural", a exemplo da proposta dos autonomistas, como Guy Débord, que centralizavam sua rebeldia em relação à "sociedade do espetáculo". A questão, agora, se refere a mudanças relativas à própria inserção individual na produção e na vida cotidiana, em que a ideologia se individualizou no tempo de cada um de nós. O curso da objetivação se dá em direção a uma subjetivação extrema, rumo à perda da referência objetiva, em decorrência de uma homogeneização qualitativa. O processo de valorização parece prescindir do outro como objeto - assim como a acumulação financeira parece prescindir da produção -, em uma experiência que se apresenta como vivência estritamente individual. Há um esgarçamento do tecido social. Mas, de forma paradoxal, é apenas a recuperação da realidade da própria geração da "experiência" como mercadoria - tal qual na "sociedade do espetáculo" - que possibilita a sua superação. Como já argumentado seguidas vezes, não basta a crítica imediata às formas assumidas pela objetivação social no interior da esfera pública burguesa. Essa visa, sobretudo, a acumulação do capital e impõe limites à 
atuação individual tanto de burgueses quanto de proletários, como atesta a mudança estrutural a que se refere Habermas em Mudança estrutural da esfera pública. A inversão da orientação da esfera pública, da crítica à legitimação, neutraliza, inclusive, a interferência dos próprios burgueses na sociedade. Assim, a esfera pública está centrada em um controle continuado, no qual a abstração da produção de mercadorias constitui uma tendência histórica permanente, não obstante as metamorfoses do capital.

A crítica à mercantilização e à espetacularização da política, à política gerencial sem transformações estruturais, à desmontagem do estado do bem-estar etc. se torna inócua, quando a alternativa - realizada, agora, de modo exacerbado, nos parâmetros dos nexos em rede - "perde sua vida no nível abstrato da organização da esfera pública", como afirmam Oskar Negt e Alexander Kluge (MARCONDES, 1988, p. 132). Esfera pública como tendência hoje mais incisiva do capitalismo, de acordo com um "esquema que, atuando de volta à base, destrói ligações solidárias, separa os indivíduos e os grupos entre si e os reunifica de forma somente mecânica" (p. 132). Está em causa a possibilidade de manter viva outra experiência, em uma esfera pública alternativa que, a rigor, seria uma esfera pública direcionada em sentido contrário, sustentada, de fato, no trabalho vivo e em sua temporalidade e não na legitimação do mercado e seu tempo. Mas não é possível reinterpretar e reconduzir, de modo imediato, essa prática quantitativa ao plano real efetivo, como ensina a crítica de Marx a Feuerbach. É preciso abandonar nossa inserção no plano dos "hegelianos de esquerda", ser efetivamente materialista e abrir espaço ao processo real de educação e formação.

Só ensaiando uma prática continuada e de associação em novos termos temporais, mediante a experiência de novos hábitos, pode-se superar o isolamento e a atomização. A educação para a resistência e a contradição deve ter como objetivo atual facultar uma tal experiência. É a experiência da contraposição entre práticas "convocadas pela rede" e práticas avaliadas, discutidas e combinadas em interação viva e concreta das pessoas. Não se trata de recusar a rede social, mas criticar o modo irrefletido de assimilação de suas práticas. É a experiência do divórcio entre o tempo da rede e o tempo da experiência. Essa é a educação para a contradição e resistência à homogeneização mercantil que se requer. Pela mesma, os homens socializados seriam novamente aptos a controlar seus destinos com autonomia, frente às imposições com que se defrontam em sua participação nos termos vigentes, decorrentes de seu próprio modo de produzir sua vida, em interação na sociedade e em interação com a natureza. 


\section{EDUCATION AT A TIME OF NETWORKING OR: WHAT HAPPENED TO AUTONOMY?}

ABSTRACT: This study set out to interpret the direction and possibilities for education according to the tendencies present under the conditions which Manuel Castells calls a network society. The analysis is based on contributions from Rousseau and Marx, especially on autonomy and society which gave rise to Adorno and Marcuse's critical theory of society. The practices of the financial networks were transferred to the social networks in the capitalism of the network society, without paying any attention to the differences between the timing of finances and that of human lives. Against this background, the study highlights the actuality of Adorno's education for contradiction and resistance as a critical educational process based on the experience of difference and contradiction. Such a process confronts, on the one hand, with agreed virtual practices developed in the existing network education and, on the other, alternative practices occurring in objective and qualitative social interactions.

Keywords: Autonomy. Network society. Participation. Theodor Adorno. Critical education.

\section{EDUCACIÓN EN LOS TIEMPOS DE LA CONECTIVIDAD EN RED O: ¿QUÉ PASÓ CON LA AUTONOMÍA?}

RESUMEN: Este texto trata de interpretar los rumbos y las posibilidades de la educación de acuerdo con las tendencias actuales bajo las condiciones de lo que Manuel Castells llama sociedad en red. El análisis se basa en las contribuciones de Rousseau a Marx - especialmente en relación con la incautación de la autonomía y de la sociedad sobretodo en lo que se refiere a la autonomía de la sociedad - que dirigieron la teoría crítica de la sociedad de Adorno y Marcuse. En el capitalismo de la sociedad en red, hubo una transferencia de la práctica de las redes financieras a las redes sociales, sin llevar en cuenta la diferencia entre el tiempo de las finanzas y el tiempo de las vidas humanas. Con respecto a ese panorama, se busca señalar la actualidad de la educación para la contradicción y la resistencia de Adorno como proceso educacional crítico basado en la experiencia de la diferencia y de la contradicción. En ella, se contraponen, por una parte, prácticas combinadas con la educación existente en la conexión en redes, con la participación virtual, y, de otro lado, prácticas alternativas en interacciones sociales objetivas y cualitativas.

Palabras Claves: Autonomía. Sociedad en red. Participación. Theodor Adorno. Educación crítica. 


\section{NOTAS}

1. A primeira versão deste texto foi apresentada como Aula Inaugural do Programa de Pós-Graduação - Educação: História, Política, Sociedade - da PUC-SP, em agosto de 2013.

2. ROSA, João Guimarães. Ficção completa - II. Rio de Janeiro: Nova Aguilar, 1994. p. 46. 3. ROSA, 1994, p. 251.

4. Ver, a esse respeito, a excelente contribuição ao estudo de Kant e Hegel. In: WOLFDIETRICH SCHMIED-KOWARZIK. Pedagogia dialética. São Paulo: Brasiliense, 1983.

5. A esse respeito, ver o meu ensaio "Reificação como realidade social". In: ANTUNES, R.; REGO, W. (Org.). Lukács - um galileu no século XX. São Paulo: Boitempo, 1996. p. 34-53.

6. Para aprofundar a questão, ver o meu artigo "Adorno, semiformação e educação". Revista Educação \& Sociedade, Campinas, v. 24, n. 83, p. 459-476, 2003. Dossiê: Adorno e a Educação.

7. Para aprofundar a questão, ver o meu artigo "Esfera pública como conceito dialético: ilusão e realidade". Revista Problemata, João Pessoa, v. 3, n. 2, p. 200-217, 2012. Dossiê: 50 anos do livro Mudança estrutural na esfera pública.

\section{REFERÊNCIAS}

ADORNO, T. W. Sociologia. São Paulo: Jorge Zahar, 1986. . Educação e emancipação. São Paulo: Paz e Terra, 1995. . Minima moralia. Rio de Janeiro: Azougue, 2008.

BENJAMIN, W. A obra de arte na época de sua reprodutibilidade técnica. São Paulo: Zouk, 2012.

BOLTANSKI, L.; CHIAPELLO, È. O novo espírito do capitalismo. São Paulo: Martins Fontes, 2009.

BRUNHOFF, S. et al. A finança capitalista. São Paulo: Alameda, 2010.

CASTELLS, M. O poder da identidade. São Paulo: Paz e Terra, 2010a. . A sociedade em rede. São Paulo: Paz e Terra, 2010b. . Fim de milênio. São Paulo: Paz e Terra, 2012.

HEGEL, G. Fenomenologia do espírito. Petrópolis: Vozes, 1992. . Discursos sobre educação. Lisboa: Colibri, 1994. . Prefácios. Lisboa: Casa da Moeda, s/d.

HORKHEIMER, M.; ADORNO, T. W. Dialética do esclarecimento. São Paulo: Jorge Zahar, 1985.

KANT, I. Crítica da razão pura e outros textos filosóficos. São Paulo: Abril Cultural, 1974. 
. Textos seletos. Petrópolis: Vozes, 1985.

MARCONDES, C. (Org.). A linguagem da sedução. São Paulo: Perspectiva, 1988.

MARCUSE, H. A ideologia da sociedade industrial. Rio de Janeiro: Jorge Zahar, 1982.

. Cultura e sociedade. v. 2. São Paulo: Paz e Terra, 1998.

MARX, K. Manuscritos econômico-filosóficos e outros textos escolhidos. São Paulo: Abril Cultural, 1978.

OLIVEIRA, F. et al. (Org.). A era da indeterminação. São Paulo: Boitempo, 2007.

ROUSSEAU, J-J. Discurso sobre a origem e os fundamentos da desigualdade entre os homens. Brasília/São Paulo: UnB/Ática, 1989.

SCHILLER, F. A educação estética do homem. São Paulo: Iluminuras, 2011.

SERRES, M. Polegarzinha. Rio de Janeiro: Bertrand Brasil, 2013.

WEBER, M. A ética protestante e o espirito do capitalismo. São Paulo: Companhia das Letras, 2004.

Wolfgang Leo MAAR é mestre e doutor em Filosofia pela Universidade de São Paulo com pós-doutorado na Universität Kassel, Alemanha; pesquisador-colaborador do Cenedic-USP. Experiência na área de Filosofia e Teoria Política, com ênfase em História da Filosofia Contemporânea, principalmente nos seguintes temas: Idealismo alemão, Dialética, Marx e marxismo, Teoria crítica, Adorno, Habermas, Teorias políticas contemporâneas.

E-mail:wmaar@ufscar.br 